\title{
PRÁTICAS EDUCATIVAS PARENTAIS E SEUS EFEITOS NA CRIAÇÃO DOS FILHOS
}

\section{Parental education practices and their effects about children rearing}

\author{
Elza Maria Canhetti Mondin \\ Participante do G rupo de Pesquisa da Universidade do O este Paulista - UNOESTE - Presidente Prudente - SP. D outora em \\ Educação. Endereço: Rua Maria Barbosa, 156 - Vila Sales. PresidenteVenceslau, SP - Brasil, e-mail: elzamondin@ hotmail.com
}

\section{Resumo}

O presente estudo está baseado em uma tese de doutoramento apresentada pela autora em 2006. Uma parte dela tratou das práticas parentais e de seus impactos sobre a educação dos filhos em idade pré-escolar. Neste trabalho é apresentada uma revisão de literatura sobre questões relativas à dinâmica familiar, nos enfoques ecológico e comportamental, objetivando descrever os efeitos das práticas educativas parentais no desenvolvimento infantil. A luz das evidências retratadas pela literatura pesquisada, discute-se aimportância: (a) da ênfase às práticas parentais positivas e suas implicações na criação dos filhos; (b) da análise do papel dos contextos familiar, econômico, social e cultural nos relacionamentos pais e filhos; (c) da necessidade de estratégias de apoio às famílias, visando melhorar a qualidade dessas interações no microssistema familiar.

Palavras-chave: Família; Práticas educativas; Crianças pré-escolares; Relacionamento pais e filhos.

\begin{abstract}
The present issue is based on a doctoral thesis completed in 2006 by the author. Part of it deal with parental practices and their impacts about preschool education. A literature review focusing ecological and comportmental familiar dynamic, is presented in this work, aiming to describe parental educational practice outcomes about children development. It is considered the significance, based on evidences featured by the literature researched: (a) from the emphasis to the positive parental practices and their implications with children's rearing; (b) from analyses of the cultural, social, economical and familiar role contexts in parent-children relationship; (c) the need of familiar support strategies, aiming to improve the interaction quality in the family microsystem.
\end{abstract}

Keywords: Family; Childrearing practices; Preschool children; Parents-children relationship. 


\section{INTRODUÇÃO}

Muitos estudos têm sido conduzidos para analisar o papel das práticas educativas e seu impacto sobre o desenvolvimento das crianças, tanto em nossa sociedade como em todo o mundo.

A os investigadores da família, tem surgido, com muita frequência, a questão de saber as razões por que algumas famílias são capazes de funcionar com relativa facilidade e até de "crescer e enriquecer", enquanto outras, frente a transições similares, não funcionam e desenvolvem perturbações mais ou menos graves. Nesse sentido, é preciso levar em conta a evolução do contexto familiar com o tempo. Toda família apresenta um ciclo de vida. Existem períodos estáveis, outros de reorganização ou de crise. As interações dentro da família modificam-se em razão do surgimento de acontecimentos relacionados a desemprego, divórcio, doença, acidente, nascimento, etc. Poucas famílias podem enfrentar esses estresses eas tensões decorrentes sem apoio externo.

D e acordo com Zamberlan (2003, p. 1314), é preciso considerar que:

A sociedade tem sofrido intensas e profundas transformações nos vários níveis que a compõem: econômico, cultural, de valores, etc. O grupo familiar, por conseguinte, acompanha essas transformações. Nas três últimas décadas, vem acontecendo uma transformação da configuração da família, com mudanças nos padrões defuncionamento entreseusmembros, principalmente no que diz respeito às famílias reconstituídas. A coexistência na sociedade de diferentes arranjos familiares modificou 0 conceito de família eprovocou um processo de assimilação e formulação de novos valores e práticas nessa instituição. A passagem de um modelo a outro tem exigido dos membros da família uma adaptação às mudanças de relacionamento, nos papéis da organização e estrutura familiar, assim como das respostas que esta passou a dar às demandas do ambiente.

É importante, lembra a autora, que a família continua a ser a principal influência norteadora do desenvolvimento da personalidade da criança e, por isso, as relações que porventura sejam inadequadas entre os pais e suas crianças constituir-se-ão em um campo fértil de estressores para seus membros.
A criação dos filhos e mais as adversidades na família frequentemente predizem problemas que parecem estabilizar-se na entrada da escola. A habilidade dos pais em encontrar as necessidades de suas crianças para orientar e apoiar, intercambiando emoções positivas, pode revelar 0 grau do desenvolvimento deconfiançae boavontade para relacionar-se com os outros através de meios positivos. Cuidados arbitrários e inconsistentes de negação e/ ou rejeição, denunciam, provavelmente, o surgimento de problemas que, umavez emergidos, alimentarão a cólera, a frustração, a desconfiança, a agressão ou altos níveis de ansiedade nas crianças.

Lubi (2003) explica que o desenvolvimento de habilidades sociais na primeira infância está vinculado de forma intensa ao contexto familiar, às vivências e às práticas educacionais. Considerando a importância dessas práticas como um fator de proteção e de maximização do desenvolvimento infantile desuapossível ligação com o envolvimento parental, este estudo teve por objetivos: (a) analisar as práticas educativas na família e seus impactos no desenvolvimento infantil; (b) considerar o contexto familiar integrado aos contextos mais amplos (econômico, cultural, político e social); (c) sugerir uma rede de suporte às famílias, auxiliando os pais no desenvolvimento das funções de paternidade e maternidade para promoverefavoreceraautonomia do núcleo familiar, no seu conjunto. Estas funções parentais constituem-seem um dos maisimportantes elementos capazes de reduzir as dificuldades de relacionamento na família, favorecendo o bemestar de todos os seus membros.

\section{A família e a criança}

De acordo com Lubi (2003), os pais, enquanto formadores do núcleo familiar, são, indiscutivelmente, poderosa fonte de influência no desenvolvimento da criança, o que lhes atribui grande responsabilidade. Os pais são os maiores reforçadores, fontes de afeto e também modelos de aprendizagem para as crianças.

As pesquisas de Pettit, Bates e D odge (1997) colocam a questão seguinte: 0 possível impacto do apoio dospais sobre o ajustamento escolar de crianças, analisado antes da entrada na pré-escola e, posteriormente, na quarta série. Trata-se de um estudo longitudinal de sete anos, em que medidas de criação de crianças foram obtidas antes da entrada no Jardim 
da Infância e, novamente, no final dos sete anos. Alguns tipos de comportamento de criação de filhos considerados como de apoio positivo foram examinados. Estes consistiram do uso de técnicas de disciplina indutiva, o interesse e o envolvimento em contatos de crianças com seus pares e ensino ativo de habilidades sociais. Os autores basearam-se na ideia de que 0 ensino ativo de habilidades sociais, 0 interesse e o envolvimento na vida social da criança poderiam estar associados com as habilidades sociais nas relações com seus pares; em razão da evidência, sugere-se que essas qualidades de criação dos filhos promovem 0 desenvolvimento social e expectativas em relação ao repertório comportamental dos relacionamentos, ao crescimento social e cognitivo da criança.

O utra questão desenvolvida nesta pesquisa referiu-se ao apoio dos pais, que poderia moderar ou minimizar o impacto da adversidade familiar sobre os efeitos na criança. Esta adversidade aqui citada refere-seàs variáveis sociais associadas aum crescente risco para mau ajustamento: status socioeconômico baixo, lares de pais solteiros e famílias estressadas. Pettit et al. (1997) associaram níveis baixos de ajustamento positivo e altos níveis de problemas comportamentais, resultantes de práticas ineficazes de criação, com problemas econômicos da família, como saláriosinstáveis, desemprego eendividamento. O s resultados desta pesquisa sugerem que a qualidade da criação positiva e de apoio dos pais desempenha um papel amenizador de alguns riscos associados às adversidades na família, tais como problemas socioeconômicos, pais solteiros e estresses familiares. $\mathrm{E}$, finalmente, este estudo fornece evidências de que as qualidades da criação com apoio, desenvolvidas nos anos iniciais da vida, podem prognosticar adaptacões bem-sucedidas através dos anos escolares. Os pais que desenvolvem práticas como discussões calmas, pacíficas e outras abordagens indutivas em confrontos disciplinares, incutem em suas crianças um senso de respeito para perspectivas contrastantes e uma crença de que as disputas podem ser resolvidas através de meios não aversivos.

É oportuno acrescentar os estudos de Roberts, Wasik, Caste Ramey (1991). Esses autores, baseados na necessidade de uma política dirigida a um serviço de apoio familiar em casa, referem-se ao papel dos pais no crescimento da criança e suas dificuldadesnesse caminho, ajudando-osa encontrar maneiras positivas na criação dos filhos, em lugar de culpá-los pelos problemas surgidos. Essa rede de apoio proposta nesses estudos foi baseada nas seguintes suposições: a) os pais são as pessoas mais consistentes em oferecer cuidados às suas crianças; b) quando os pais são providos de conhecimentos e habilidades para fornecerem uma criação de apoio, responderão mais efetiva e positivamente às suas crianças; c) mudanças estruturais em famílias, tais como pais solteiros, alta incidência de nascimentos entre adolescentes, negligência familiar, casamentos rompidospelo divórcio, condições socioeconômicas e pobreza. 0 contexto social assim configurado vai exigir, certamente, que se enfoque a família como um sistema social (microssistema) que necessita de apoio psicológico e informativo a respeito do desenvolvimento da criança e modos positivos de sua criação. É um processo através do qual se pode avaliar as prioridades da família, transmitir informações, promover suporte e encorajamento, autoconfiança e esforços efetivos no sentido de mudança de algumas práticas que têm influenciado negativamente as relações entre pais e filhos.

\section{Os problemas de comportamento}

A procura por atendimento psicológico, explica Marinho (2001a), para auxílio de problemas de comportamentos apresentados por crianças, tem aumentado muito nas últimas décadas, especialmente pelas dificuldades que inúmeras famílias têm encontrado para educar seus filhos em um ambiente consideravelmente distinto do qual foram educadas. Um dos pontos básicos no processo de educação infantil, continua a autora, refere-se ao desenvolvimento da autoestima (é a maneira pela qual uma pessoa se sente em relação a si mesma; é o juízo geral que faz de si mesma, 0 quanto gosta de sua própria pessoa). A autoestima da criança e 0 afeto familiar estão interligados, como revela Marinho (2001a, p. 13):

A criança precisa sentir que é amada na vitória e naderrotacom amesmaintensidade. Acreditando que amar os filhos não é um instinto (como em instinto materno), mas um conjunto de comportamentos, fruto de contingências, devemos identificar quais são as variáveis envolvidas em suaocorrênciaou não. Ajudarpais aamarem seusfilhosincluiajudá-losaaceitar suas crianças como pessoas inteiras que buscam aprender a melhor forma de agir neste mundo e ser feliz. Ajudá-los a valorizar a vida ali presente. 
É necessário esclarecer aos pais que os comportamentos valorizados pela família e esperados que sejam apresentados pela criança devem ser ensinados. Além disso, é fundamental acrescentar que 0 ser humano vive em comunidade; esse comportar-se deve, obviamente, levar em conta uma importante parte do ambiente: as pessoas. Gomide (2001) explica que as diferentes maneiras utilizadas pelos pais no cuidado de seus filhos podem estar correlacionadas tanto com o desenvolvimento saudável da criança como podem vincular-se ao desenvolvimento de comportamentos antissociais. Por exemplo, a monitoria, aparentemente, é um poderoso inibidor do desenvolvimento de condutas antissociais em crianças e adolescentes; jáa negligência e o espancamento apresentam alta correlação com comportamentos infratores. 0 abuso físico, caracterizado por maus-tratos e/ ou espancamento, aumenta poderosamente as chances de a criança desenvolver repertório agressivo ou infrator. Esse tipo de punição, alerta G omide (2001, p. 38):

é acompanhada por raiva, com ausência de informações por parte do agente punidor sobre a especificidade da punição. A criança agredida verbal e fisicamente recebe do ambiente (pais ou educadores) informações afetivas e cognitivas negativascom tal intensidadeque passaa avaliar-se como um ser execrável eindesejável. Esta "prática educativa" permite quea criança se percebacomo um ser nuim e não informa as regras de conduta que deveriam ser seguidas para evitar tal conseqüência. Visto queapunição éparatodo ser, não existem, do ponto devistadacriança, altemativas comportamentais que sejam capazes de inibir 0 espancamento. Assim, a criança espancada pode vir a acreditar queé um ser num, merecedor desta ação. A partir desta autopercepção, seus comportamentos inadequados, infratores, agressivos, enfim, anti-sociais, podem se tomar manifestos, ou seja, ela aprende que "seres maus" apresentam comportamentos maus.

E conclui, com as palavras de Sidman, "a punição podeproduzirapaz que ospais desesperados necessitam, às custas dos inevitáveis efeitos colaterais - mas não oferece à criança qualquer caminho alternativo de ação, nenhum caminho para adaptarse construtivamente" (Gomide, 2001, p. 38).

Marinho (2001b), baseada em estudos de Patterson, expõe quatro estágios, mostrando como ocorre o desenvolvimento do comportamento antissocial que seiniciano ambientefamiliarchegando até à delinquência. 0 primeiro estágio desenvolve-se na família, onde os pais descrevem a criança como difícil, diferente dosirmãos, mas isso não é motivo de preocupação e que ela não precisa de ajuda. Uma disciplina ineficiente por parte dos pais é observada, com pouca monitoria das atividades da criança; seu temperamento abrasivo é identificado nessa fase. 0 segundo estágio ocorre no ambiente escolar, onde começam as reclamações a respeito da criança, tais como: é inadequada à classe, pois faltam-lhe habilidades para aprender; apresenta baixa probabilidade de se relacionar bem com seus pares e de desenvolver habilidades sociais e acadêmicas. 0 terceiro estágio indica a reação do meio social ao rejeitá-la; a criança é impulsionada a buscar apoio em ambientes alternativos. E, o último, quarto estágio, revela 0 adolescente internado em instituições, seja hospitalar, educacional ou correcional. Similarmente, Bolsoni-Silva e Marturano (2002) descrevem uma progressão desenvolvimentista para problemas de comportamento, a qual pode assumir dupla direção. A primeira, chamada de early starter, descreveria comportamentos agressivos e opositivos, no período dapré-escola, podendo progredirparaa agressividade esintomas deproblemascomportamentaisno período escolar ulterior; tais sintomas podem se tornar mais sérios na adolescência, emergindo como violência interpessoal e violações de propriedade. O s locais de ocorrênciadecomportamentosperturbadorestendem a aumentar com o passar do tempo, ou seja, de casa ou pré-escola para locais escolares e, finalmente, para comunidades mais amplas. A segunda possibilidade, chamada later starter, ao contrário, considera os casos que surgem na adolescência.

As interações entre pais e filhos são apontadasporConte(2001) como sendo os principais fatores determinantes dos comportamentos antissociais. Os maus-tratos para com a criança, a negligência e rejeição dos pais, a disciplina rígida e inconsistente ou flácida e relaxada, altamente permissiva e inconsequente, a falta de apoio dos pais, vínculos familiares fracos, brigas entre os pais e entre pais e filhos são destacados pela autora.

\section{As práticas educativas e seus efeitos no comportamento infantil}

Há indicação de condutas parentais consideradas positivas e protetoras do desenvolvimento, esclarece Conte (2001), que relaciona as 
seguintes: a) uma condução calorosa, demonstrando a aceitação da criança, a sua valorização pessoal, além do apoio às suas iniciativas; b) encorajamento ao desenvolvimento de competência social; c) frequência de interações mais positivas do que mais aversivas; expressão contínua de afeto positivo; d) modelos apropriados de pais que favoreçam a identificação das crianças com eles; e) incentivo ao desenvolvimento da autonomia, como a capacidade de fazer escolhas e da promoção da autodireção; f) aplicação de métodos racionais e verbais de disciplina; g) minimização de brigas e agressões entre os familiares. Com base nesses itens mencionados, diz a autora:

Enquanto muitospais conseguem caminharnesta direção, outros não têm a mesma evolução. Isso decorre, em primeira instância, como já foi dito, de fatores que não estão relacionados à criança, como é o caso da experiência anterior do pai em sua família de origem e ao padrão de interação ocorrido entre ele e os seus próprios pais. Tais experiênciassão importantesno desenvolvimento deseu repertório de "serpai" (seu estilo parental), em conseqüência dos processos de modelagem e de modelação que se sucederam. Um outro fatorinfluente, narelação pais/ filhos relaciona-se à irritabilidade pessoal, decorrente de estresse atual ou de vida crônica estressante. Tal estresse, por sua vez, pode decorrer de problemas conjugais, econômicos ou profissionais; da falta de apoio, ausência de companheiro à mãe ou de companheirismo entre os pais, entre outros. (Conte, 2001, p. 163).

Ingberman (2001) relaciona alguns aspectos da dinâmica familiar que contribuem para 0 ajustamento de seus membros. 0 primeiro indica a comunicação, qualquer comportamento verbal ou não verbal manifestado por seus membros. 0 segundo aspecto refere-se às regras familiares: a introdução da disciplina na vida da criança envolve um contexto de interação entre pais e filhos, em que a criança começa a ser confrontada com as regras das práticas educativas parentais. As práticas de manejo parecem provocar um impacto significativo sobre o comportamento infantil, como ilustra Marinho (2001b, p. 206):

Quando os pais anti-sociais ou com fraca capacidade de manejo da criança são colocados diante de um estresse agudo e prolongado, rupturasimportantesnapráticadaadministração familiar são fáceis de ocorrereéestarupturaque coloca a criança em situação de risco. Assim, existe evidência de que a prática de disciplina parental possa ser um mecanismo importante na transmissão do comportamento anti-social de uma geração a outra.

0 terceiro aspecto refere-se aos papéis familiares em que cada elemento assume papéis definidos e adequados, contribuindo para 0 ajustamento total da família. 0 quarto aspecto envolve a liderança que os pais devem exercer no grupo familiar, mas compartilhada com os filhos de modo diferenciado e democrático, buscando 0 crescimento emocional de todos.

Gottman e De Claire (1997) citam a paternidade "com autoridade", expressão usada por Baumrind, e lembram que a característica dos pais autoritários é impor muitos limites e esperar obediência estrita da criança sem lhe dar explicações; os pais "com autoridade" impõem limites, mas são consideravelmente mais flexíveis e dão muitas explicações e muito carinho aos filhos. Os conflitos referem-se ao quinto aspecto epodem ser benéficos, ou não, à medida que estimulem ou predisponham ao desequilíbrio emocional. Cabe à família conter os efeitos destrutivos dos conflitos e buscar suas soluções. O sexto aspecto lembraqueamanifestação da agressividade pode ocorrer no ambiente familiar, mas sua expressão deve ser usada de forma construtiva. A afeição física deve estar presente e ser manifestada com carga emocional adequada. $\mathrm{O}$ sétimo aspecto diz respeito à interação conjugal para a integração e a coordenação de esforços para os objetivos comuns. Marinho (2001b) inclui o baixo grau de envolvimento positivo da família com a criança e o pobre monitoramento e supervisão das atividades desta, como fatores relevantes no desenvolvimento de comportamentos infantis antissociais. Os pais, na visão de Gottman e De Claire (1997), que não impõem limites e tampouco procuram orientar o comportamento de suas crianças, resulta em que estas apresentam dificuldades para concentrar-se, em fazer amizades e em relacionar-se com seus pares. Hart (1992, p. 36) refere-seà permissividadeafirmando que "muitos pais pensam que seus filhos se sentem amados porque podem fazer o que desejam. As crianças precisam de limites seguros, saudáveis e razoáveis, enossa disposição em colocar esses limites transmite amor". E conclui: "Se vocês encontrarem tempo para conversarem todos os dias, jamais se tornarão 
estranhos." E, por fim, o oitavo aspecto diz respeito à autoestima. O s pais, quando se interessam desde cedo pelas realizações de seus filhos, certamente estarão desenvolvendo os sentimentos de valor que cada um tem em relação a si próprio. Crianças maltratadas tendem a ser retraídas, a ter pouca autoestima e a mostrar padrões reativos de hostilidade e agressividade, alerta Falcone (2000).

Menção especial merece, a esse respeito, as palavras de Brazelton e G reenspan (2002, p. 4): "Q uando há relacionamentos seguros, empáticos, sustentadores, as crianças aprendem a ser íntimas e empáticas e eventualmente a comunicar seus sentimentos, refletir sobre seus próprios desejos e desenvolver seus próprios relacionamentos com seus iguais e com os adultos."

Os autores explicam que os relacionamentos no contexto familiar possibilitam à criança observar quais comportamentos são adequados e quais não são.

As crianças que não são capazes de relacionar-se com as pessoas de maneira afetuosa e confiante - crianças que são distantes, retraídas e desconfiadas - tornam-se isoladas e dificilmente estão disponíveis a ouvir as outras pessoas e devem contar apenas com seus próprios pensamentos ou experiências. Enfim, perdidas em suas próprias sensações, sentimentos e pensamentos, podem tornar-se - até certo ponto - alienadas da realidade e do mundo da lógica e da objetividade.

0 desenvolvimento do comportamento antissocial, explica Marinho (2001b), é marcado por uma sequência mais ou menos previsível de experiências. Inicialmente, as práticas de ação ineficientes dos pais são vistas como determinantes do problema de comportamento na criança. Em segundo lugar, esse comportamento infantil leva ao fracasso acadêmico e à rejeição pelos colegas, e isso, por sua vez, acarreta um aumento no risco de depressão e envolvimento com grupos de rejeitados.

Crianças rejeitadas são extremamente vulneráveis a dificuldades de ajustamento na infância, adolescência e vida adulta, alerta Gomes da Silva (2001), e tendem a ser mais agressivas, não cooperativas e não obedientes às regras. Assim, é possivel afirmar, conforme Marinho (2001b), que os problemas de comportamento apresentados pelas crianças são devidos, principalmente, ao padrão de interação familiar; às competências infantis, tais como assertividade e expressividade emocional são altamente correlatas às respostas dos adultos e à aceitação social nainfância, além de serem importantes preditores de normalidade na idade adulta.
Em suas pesquisas, Alvarenga (2001) relaciona as práticas educativas dos pais na educação de suas crianças, classificando-as em não coercitivas/ coercitivas e seus efeitos no comportamento infantil. A s práticas não coercitivas ou indutivas podem ser definidas como o uso ou manipulação de reforçadores positivos, bem como autilização de regras que descrevem consequências naturais no controle do comportamento da criança.

D entre as práticas não coercitivas, além das explicações apontando consequências, Alvarenga (2001) indica a negociação/troca, explicação baseada em convenção, comando verbal não coercitivo e mudança nos hábitos da criança.

D o ponto de vista da abordagem ecológica, as relações de amizade e a adaptação a diversos ambientes são permeadas pelas transições ecológicas (Bronfenbrenner, 1996). As transições ecológicas ocorrem quando a criança começa a ampliar suas relações, passando a conviver com outros microssistemas, além do original (família). A transição da criança para outros microssistemas (escola, vizinhança, parentes) requer 0 exercício de novos papéis, específicos para cada contexto. A habilidade da criança nesse campo é considerada um importante aspecto da competência social, visto que está relacionada com a adaptação a diferentes contextos.

Uma criança socialmente competente, explicam Cecconello e Koller (2000), é capaz de ser sensível e empática com seus pares, de se engajar em atividades sociais positivas, formar relações de amizade e adaptar-se a situações de estresse. Cecconello, De Antoni e Koller (2003) explicam que as práticas coercitivas, como a punição, condicionam ainibição dos comportamentosinfantis reprimidos pelos pais. As sanções punitivas podem eliciar sentimentos negativos nas crianças, inibindo a produção de comportamentos, devido à ansiedade gerada por elas mesmas ou por sua ameaça. Esclarecem as autoras que os modelos de estilo apresentam duas dimensões, o da exigência e o da responsividade. A combinação dessas duas dimensões resulta em quatro estilos parentais. A exigênciadiz respeito aos comportamentos parentais que requerem supervisão e disciplina. A responsividade diz respeito aos comportamentos de apoio e aquiescência, facilitadores da autoafirmação e daindividualidade dosfilhos. D esse modelo derivam os estilos parentais autoritativo, autoritário, indulgente e negligente. Com relação ao primeiro estilo, as autoras explicam que: 
[...] resulta da combinação entre exigência e responsividadeem altosníveis. Pais autoritativos estabelecem regras para o comportamento de seus filhos, que são consistentemente enfatizadas. Eles monitoram a sua conduta, corrigindo atitudes negativas e gratificando atitudes positivas. A disciplina é imposta de forma indutiva e a comunicação entre pais e filhos é clara e aberta, baseada no respeito mútuo. São pais que têm altas expectativas em relação ao comportamento dos filhos em termos deresponsabilidadeematuridade. Além disso, são afetuosos na interação com eles, responsivos às suas necessidades e, freqüentemente, solicitam sua opinião quando conveniente, encorajando atomadade decisões e proporcionando oportunidades para 0 desenvolvimento de suas habilidades (Cecconello et al., 2003, p. 48).

O segundo estilo, 0 autoritário, prosseguem as autoras, caracteriza-se por altos níveis de controle e baixa responsividade. Em nome do respeito e da obediência, os pais fazem uso frequente da punição como forma de controle comportamental. O diálogo, a autonomia e as opiniões da criança não são valorizados. 0 terceiro estilo, o indulgente, combina baixo controle e alta responsividade. Regras e limites não são estabelecidos. O s pais indulgentes são tolerantes, liberando a criança para controlar seu próprio comportamento. $\mathrm{O}$ quarto estilo, o negligente, caracteriza-se por baixos níveis de controle e responsividade. Pais negligentes não se envolvem na tarefa de educar os filhos, não são afetivos e nem exigentes; preocupam-se apenas com sua própria vida.

As estratégias de força coercitiva, segundo Alvarenga (2001), são caracterizadas pela aplicação direta da força, incluindo punição física, privação de privilégio e afeto, ou pelo uso de ameaças. Essas técnicas fazem com que a criança controleseu comportamento em função das reações punitivas dos pais. Além disso, elas produzem emoções intensas tais como medo, raiva e ansiedade, que tendem a reduzir ainda mais a possibilidade de a criança compreender a situação eanecessidade demodificação do comportamento. Nesse sentido, as estratégias de força coercitiva não favorecem a internalização das regras sociais e padrões morais. As relações entre práticas de caráter coercitivo e problemas de comportamento têm sido frequentemente reportadas na literatura.
Essas relações são ilustradas pela autora como: a) diferentes tipos de problemas comportamentais, como os de externalização (= comportamento agressivo, desobediência, etc.); b) o afeto, somado a uma atitude educativa e positiva da mãe, estaria, de modo consistente, relacionado à ausência de problemas de comportamento; c) foi revelada, em crianças pré-escolares, uma correlação positiva entre 0 uso de punição física e a presença de problemas de comportamento, assim como uma correlação negativa entre práticas educativas não coercitivas e problemas de comportamento.

De acordo com Weber, Viezzer e Brandenburg (2003, p. 499), para muitos pais: a punição física é considerada a melhor forma de disciplinar os filhos. Justamente pelo fato de a punição ser tão utilizada, nós buscamos compreender de forma mais precisa o que explicaria tal comportamento dos pais.

De fato, quando apanha, a criança, na maioria das vezes, para imediatamente de emitir 0 comportamento.A imediata obediênciatraz benefício para os pais, aumentando a probabilidade de continuarem a utilizar tal prática em situações ulteriores.

O s pais, explicam as autoras, precisam ter acesso ao conhecimento de outras práticas educativas que garantam a criação e a manutenção de um repertório comportamental adequado, como o de auxiliar o desenvolvimento de habilidades sociais em seus filhos e de manter uma dinâmica familiar, com muita responsividade, afeto e comprometimento. É claro que, eventualmente, será necessária a aplicação de alguma estratégia para a redução ou eliminação de comportamentos inadequados e/ ou transgressões aos limites. Entretanto, se o uso da disciplina positiva (uso de reforçadores) for sistemática, o estabelecimento de regras (limites) for consistente e lógico, com uma supervisão constante, modelos positivos, incentivo à autonomia e fortalecimento da autoestima da criança, não sobrará muito espaço para a ocorrência de comportamentos inadequados. Os que surgirem poderão ser solucionados com estratégias menos dolorosas e indignas do que a punição física.

Pais com pobre disciplina e fraco monitoramento dos filhos, explica Löhr (2001), podem fazer com que estes não desenvolvam habilidades básicas necessárias, e apresentem baixa autoestima e condutas antissociais; por não exprimirem respostas apropriadas no manejo das 
situações no contexto familiar, essas crianças passam a ser rejeitadas na família; ao participarem de outros contextos sociais, como não aprenderam a interagir de forma apropriada, não conseguem estabelecer relacionamentos produtivosno contexto geral, sendo novamente rejeitadas.

Diferentes problemas de família, explica Bennett (2000), tais como as adversidades ambientais, abusos parentais, negligência, discórdia conjugal, podem provocar o surgimento de comportamentos agressivos na infância.

Royer (1999), ao abordar o tema referente às dificuldades emocionais e comportamentais da criança e do adolescente, revela que o crescimento e prevalência da agressividade e os comportamentos antissociais da criança e do adolescente estão fundamentados em algunsfatores como: habilidades dos pais, caracterizadas porpunições, inconsistência e a falta de limites no espaco familiar.

Coelho e Conte (2003) explicam que a criançaforma suaidentidade, desenvolve seu mundo privado e seu comportamento público a partir de sua relação com o outro. O s valores e conceitos a respeito do ambiente que a cerca são construídos nas suas relações sociais. É nesse sistema que a criança será avaliada/ julgada por seus comportamentos "virtuosos" ou "indesejáveis"' e reconhecida como pró ou antissocial. E, por essa razão, as autoras concluem que é necessário intervir o mais cedo possível em etapas mais precoces de desenvolvimento da criança.

A competência social, de acordo com Morais, O tta e Scalla (2001) é um conceito referente à capacidade de interação e de adaptação da criança ao grupo de companheiros. A investigação dessa capacidade na criança tem contribuído para a compreensão de sua importância no desenvolvimento psicossocial. Nas relações que a criança estabelece com o grupo de companheiros estão em jogo habilidades essenciais - como revezamento de papéis e adoção da perspectiva do outro, nos campos afetivo e cognitivo - e a possibilidade de experimentar a prática do poder no grupo de estratégias, assim como os mecanismos utilizados para a obtenção da aceitação e manutenção de suaposição no grupo. Essas questões são consideradas fundamentais, tanto para a resolução de problemas atuais da criança, para a solução de tarefas que enfrenta no decorrer de seu desenvolvimento, para a avaliação de pessoas que possam oferecer-lhes referentes para o apoio social, quanto para o desenvolvimento de capacidades necessárias à sua futura adaptação social. As dificuldades em competência social, conforme Morais et al. (2001), resultam em falta de amigos e em isolamento social, que tendem a despertar reações diversas, como por exemplo, a raiva, gerando comportamentos hostis e/ ou agressivos, ou a autopiedade, gerando tristeza e/ ou depressão. Crianças consideradas rejeitadas e negligenciadas, provavelmente, desenvolverão problemas de ajustamento social. Em casos de crianças consideradas controversas, a quem são atribuídas características tanto positivas - como capacidade de liderança - quanto negativas - como agressividade - cabem indagações:

Serão elas consideradas como portadoras de risco de virem a apresentar comportamentos anti-sociais e de liderança conjuntamente, ou seja, de virem a tornar-se líderes de grupos marginais? $\mathrm{Ou}$ terão elas menos risco de desenvolverem condutas anti-sociais do que as crianças rejeitadas, pelo fato de terem características positivas que podem compensar as negativas? (Morais et al., 2001, p. 120).

Quanto mais cedo forem observadas dificuldades de ajustamento social, alertam as autoras, mais prontamente será possível interferir no sentido de evitar sua instalação de maneira mais permanente e menos reversível.

Di Franco (2003, p. 2) indica:

[...] a presença de um elo que dá unidade aos recentes crimes que destruíram inúmeros lares: esgarçamento dasrelaçõesfamiliares. Háexceções, é claro. D esequilíbrios e patologias independem da boa vontade de pais e filhos. A regra, no entanto, indica que o crime hediondo costuma ser o dramático corolário de um silogismo que se fundamenta nas premissas do egoísmo e da ausência, sobretudo paterna. A desestruturação da família está, de fato, na raiz da tragédia.

Em outros trechos do artigo, o autor enfatiza que a ausência de limites e a crise de autoridade estão na outra ponta do problema:

Transformou-se o prazer em regra absoluta. 0 sacrifício, a renúncia e o sofrimento, realidades inerentes ao cotidiano de todos nós, foram excomungados pelo mark etingdo consumismo alucinado. Decretada a demissão dos limites e suprimido qualquer assomo de autoridade (dos 
pais, da escola e do Estado), sobra a barbárie. A responsabilidade, conseqüência direta dos atos humanos, simplesmente evaporou.

As palavras do jornalista, registradas acima, um tanto desoladoras, retratando o contexto social da atualidade, podem ser remetidas a Hoffman (1975), que discute o poder paterno e a natureza da interação pais-criança. Ele argumenta a respeito do conceito de poder, o qual pode ser definido como o potencial de que um indivíduo dispõe para forçar outra pessoa a comportar-se de modo contrário a seus desejos; obviamente, os pais possuem, em virtude de sua grande força, um total controle material e emocional sobre a criança. É claro que esta exerce influência sobre seus pais, sendo basicamente quem deve ajustar-se a eles, e não 0 contrário, através dos "encontros disciplinares" (= tipo de interação pais-criança, no qual os pais assumem o poder sobre o controle comportamental da criança; 0 ingrediente principal reside na predisposição em subordinar as necessidades hedonísticas em favor das exigências sociais e morais da situação, comunicadas pelos pais no início da vida). É interessante lembrar que 0 autor trata dos encontros de disciplina como os momentos em que a criança exercita o equilíbrio entre a expressão e o controle de seus desejos; assim, sugere que a técnica utilizada pelos pais indica o poder assertivo, levando a criança a ponderar seus comportamentos desejados contra as reações punitivas antecipadas de seus pais. Aqui, entretanto, vai um alerta: esse poder assertivo poderia contribuir para o desenvolvimento do controle comportamental por vias de sanções externas, provocando intensas emoções como hostilidade, medo ou ansiedade. Induções oferecem à criança uma experiência diferente: como todas as técnicas disciplinares, elas comunicam os desejos dos pais para a mudança de comportamento e pressionam a criança para a obediência. Entretanto, é possível que as induções diretas possam dirigir a atenção da criança para as consequências de seu comportamento para as outras pessoas, em vez deenfocar as consequências punitivas para ela mesma. Assim, prevê-se 0 surgimento de uma visão lógica das situações. Esse entendimento cognitivo permitirá à criança autonomia suficiente para o processamento destas informações e posterior utilização como uma base referencial para controlar a conduta.
Falcone (2000, p. 275), explica:

Quando uma criança causa algum dano a outra e seus paislevam-naa prestaratenção para o malestardavítima, estão reforçando comportamento empático e promovendo condutas pró-sociais. A quantidade de interações sociais parece estar relacionada a experiências empáticas.

E conclui que:

Os pais devem incentivar os filhos a viverem experiências variadas e emoções freqüentes, com o objetivo de estimular a sua sensibilidade frente aos sentimentos alheios. Uma criança superprotegida de experiências desagradáveis enão estimuladaamanifestar expressõesabertas de mal-estar, provavelmente terá dificuldades em empatizar com outras pessoas em apuros.

Algumas práticas educativas positivas são relacionadas pela autora: a) comportamento responsivo, não punitivo e não autoritário por parte dos pais; b) explicar aos filhos os efeitos de seus comportamentosnos outros; c) mostrar aos filhos que eles têm o poder de fazer as pessoas felizes, sendo agradáveis e generosos com elas; d) explicar aos filhos que comportamentos prejudiciais machucam e aborrecem as pessoas; oferecer-lhes sugestões para corrigirem suas falhas. As práticas educativas negativas, prossegueFalcone, são:a) corretivosatravés de ameaça e punição física para induzir as crianças a "agirem corretamente"; b) comportamento inconsistente com a expressão das necessidades delas; c) provisão de recompensas extras ou subornos para eliciar "bons" comportamentos nas crianças.

D el Prette e D el Prette (2002) relatam as três estratégias básicas de Argyle, pelas quais os pais educam seus filhos: a) por meio das consequências (recompensas e punições); b) pelo estabelecimento de normas, explicações, exortações e estímulos; c) por modelação. É importante acrescentar que, além das regras, os comportamentos dos pais são observados e copiados pelas crianças.

Namodernateoria daaprendizagem social, Saldaña, Del Prette e D el Prette (2002, p. 277), reiteram que: "Na família, por exemplo, 0 comportamento dos pais torna mais provável 0 comportamento dosfilhos, medianteaaprendizagem observacional, formando-se uma cadeia de transmissão de regras de estilo de comportamentos de pais para filhos." 
Silvares (2000) explica que existem evidências de que o domínio de relações interpessoais positivas na infância, especialmente entre pares da mesma idade, constitui-se em prérequisito básico à futura saúde mental e ao sucesso educacional do indivíduo, como também é reconhecido que as relações infantis negativas com os pares, pais e outros adultos estão associadas a resultados negativos na vida adulta. E conclui que as crianças socialmente competentes, em relação às incompetentes, são mais: a) afetivas e acuradas na percepção das dicas internas e externas dos seus pares; b) eficazes na construção de objetivos que contribuem para favorecer o relacionamento social com seus pares. Algumas variáveis são assinaladas pela autora como prejudiciais à interação familiar saudável: a) características de comportamento dos avós (comportamento antissocial e manejo familiar pobre); b) características dos comportamentos dos pais (comportamento antissocial e suscetível a estressores); c) variáveis sociodemográficas (baixa escolaridade, pertencer a grupo étnico minoritário); d) estressores familiares (desemprego, conflito marital e separação conjugal).

\section{CONCLUSÕES}

O s resultados desta pesquisa fortalecem a importância das práticas educativas na interação familiar e a necessidade de uma rede de auxílio às famílias para lidarem com as dificuldades encontradas na educação dos filhos.

Os estudos já realizados revelam reiteradamente que a educação autoritária não é a mais positiva nos dias atuais, quando a sociedade prima pela flexibilidade e espírito crítico de seus membros. Por outro lado, a adoção de práticas educativas permissivas representam um grande perigo ao desenvolvimento psicológico das crianças.

$\mathrm{E}$, finalmente, é certo pensar que pais e mães, ao construírem a prática educativa cotidiana, atuando com os filhos, fazem-no através da interação com seu contexto sociocultural. Assim, evidencia-se a necessidade de aproximação do ambiente no qual as pesquisas se desenvolvem, pois a correlação entre 0 fenômeno analisado e 0 contexto é significativa.
Esta perspectiva contextual é fundamental para o estudo do desenvolvimento das interações familiares, além de auxiliar a lidar com o problema de descrever e analisar o contexto mais abrangente no qual a família está inserida.

Repetidas vezes, Bronfenbrenner (1996) lamenta a falta de uma estrutura teórica apropriada paraanalisar osambientes em queviveo ser humano. Os conceitos que existem nesta área são limitados e indiferenciados, em que apenas fixam as pessoas em termos de endereços sociais - o ambiente de onde elas vieram. O s dados obtidos em estudos não abrangem informações a respeito do ambiente do qual as pessoas vêm, mas, a respeito das características das próprias pessoas e como elas diferem de outras originadas de outros contextos. Assim, tais comparações não contribuem para aumentar nossa compreensão de como os contextos ecológicos afetam 0 curso do desenvolvimento psicológico. Por exemplo, alguns fatores tais como status ocupacional, grau de escolaridade, tamanho dafamília, emprego damãe, famílias de pais solteiros podem produzir efeitos significantes que variam sistematicamente no tempo e no espaço.

A perspectiva contextual explica que 0 desenvolvimento humano só pode ser compreendido dentro de um contexto social. A pessoa é parte inseparável do ambiente, atua sobre ele modificando0 e, em contrapartida, 0 ambiente, em constante mutação, também atua e muda a pessoa.

Atualmente, a complexidade social e os novos riscos com os quais a família se depara (ambiente) impõem uma atenção particular ao papel dos pais.

O presente estudo reforça a importância do papel da família e do ambiente em geral, que proporcionam condições estimuladoras ao desenvolvimento infantil, e evidencia a importância de atividades de apoio às famílias, com a finalidade de auxiliá-las na estruturação, organização e enriquecimento do ambiente de desenvolvimento dos filhos.

Em suma, ressalta-se a necessidade de enfatizar, na educação familiar, as práticas educativas positivas e a prevenção de práticas negativas que impliquem comprometimentos no desenvolvimento das crianças. 


\section{REFERÊNCIAS}

Alvarenga, P. (2001). Práticas educativas parentais como forma de prevenção de problemas de comportamento. In H. J. G uilhardi, M. B. B. P., Madi, P. P. Queiroz, M. C. Scoz (O rg.). Sobre comportamento e cognição: Expondo a variabilidade. (pp. 54-60). Santo André: Esetec.

Bennett, P. P. (2000). Children with emotional and behaviour difficulties and their parents. A peer reviewed journal, 5(3), 12-17.

Bolsoni Silva, A. T., \& Marturano, E. M. (2002). Práticas educativas e problemas de comportamento: uma análise à luz das habilidades sociais. Estudos de Psicologia, 7(2), 227-235.

Brazelton, T. B., \& Greenspan, S. I. (2002). As necessidades essenciais das crianças. Porto Alegre: Artmed.

Bronfenbrenner, U. (1996). A ecologia do desenvolvimento humano: Experimentos naturais e planejados. Porto Alegre: Artes Médicas.

Cecconello, R. M., De Antoni, A., \& Koller, S. H. (2003). Práticas educativas, estilos parentais e abuso físico no contexto familiar. Psicologia em Estudo, 8(n.e.), 45-50.

Cecconello, A. M., \& Koller, S. H. (2000) Competência social e empatia: Um estudo sobre resistência com crianças em situação de pobreza. Estudos de Psicologia, 5(1), 71-93.

Coelho, M. A., \& Conte, F. S. (2003). Efeitos da relação terapêutica na redução de comportamentos agressivos de crianças de baixa renda. In M. Z. S. Brandão, F. C. S. Cont, F. S. Brandão, Y. K. Ingberman, C. C. Moura, V. M. Silva, et al. (O rg.). Sobre comportamento e cognição, clínica, pesquisa e aplicação. (pp. 97-105). Santo André: Esetec.

Conte, F. C. S. (2001). Promovendo a relação entre pais e filhos. In M. D elitti (O rg.). Sobre comportamento e cognição: A prática da análise do comportamento e da terapia cognitivo-comportamental (pp. 161168). Santo André: Esetec.
Del Prette, A., \& Del Prette, Z. A. P. (2002). Psicologia das relações interpessoais: Vivências para o trabalho em grupo. Petrópolis: Vozes.

Di Franco, C. A. (2003). Blecaute da família e da autoridade. Jornal 0 Estado de São Paulo, ano 124(40004), p. 2. Espaço Aberto. 28 abr.

Falcone, E. (2000). Habilidades sociais e ajustamento: 0 desenvolvimento da empatia. In R. R. Kerbauy (O rg.). Sobre comportamento e cognição Vol. 5: Conceitos, pesquisa e aplicação, a ênfase no ensinar, na emoção e no questionamento clínico. (pp. 273278). Santo André: Esetec.

Gomes da Silva, V. R. M. G. (2001). Reconhecendo e prevenindo a rejeição entre os pares. (2001). In H. J. Guilhardi, M. B. B. P. Madi, P. P. Queiroz, M. C. Scoz (O rg.). Sobre comportamento e cognição: expondo a variabilidade. (pp.13-19). Santo André: Esetec.

Gomide, P. I. C. (2001). Efeitos das práticas educativas no desenvolvimento do comportamento anti-social. (2001). In M. L. Marinho; V. E. Caballo (O rg.). Psicologia clínica e da saúde. (pp. 33-39). Londrina: UEL; Granada: A picsa.

G ottman, J., \& D e Claire, J. (1997). Inteligência emocional: A arte de educar nossos filhos. Rio de Janeiro: O bjetiva.

Hart, L. A. (1992). A família moderna: Uma reflexão sobre o desenvolvimento de uma relação madura e saudável entre pais e filhos. São Paulo: Saraiva.

Hoffman, M. L. (1975). Moral internalization parental power and the nature of parent: Child interaction. Developmental, Psychology, 11(2), 228-239.

Ingberman, Y. K. (2001). Terapia comportamental com famílias. In M. D elitti (O rg.). Sobre comportamento e cognição Vol. 2: A prática da análise do comportamento e da terapia cognitivo comportamental. (pp. 222-228). Santo André: Esetec. 
Lohr, S. S. (2001). D esenvolvimento das habilidades sociais como forma de prevenção. In H. J. G uilhardi, M. B. B. P. Madi, P. P. Queiroz, M. C. Scoz, M. C. Sobre comportamento e cognição Vol. 8: Expondo a variabilidade. (pp. 190-209). São Paulo: E setec.

Lubi, A. P. L. (2003). Estilo parental e comportamento socialmente habilidoso da criança com pares. In M. Z. Brandão, F. C. S. Conte, F. S. Brandão, Y. K. Ingberman, C. B. Moura, $\&$ V. M. Silva, et al. (O rg.). Sobre comportamento e cognição Vol. 11: A história, os avanços, a seleção por conseqüências em ação. (pp. 536-541). Santo André: Esetec.

Marinho, M. L. (2001a). Subsídios ao terapeuta para análise e tratamento de comportamento em crianças: quebrando mitos. In M. L. Marinho, V. E . Caballo (O rg.). Psicologia clínica e da saúde. (pp. 3-21). Londrina: UEL; $\mathrm{G}$ ranada: Apicsa.

Marinho, M. L. (2001b). Comportamento infantil anti-social: programa de intervenção junto à família. In R. R. Kerbauy, \& R. C. Wielenska (O rg.). Sobre o comportamento e cognição, psicologia comportamental e cognitiva: $\mathrm{Da}$ reflexão teónica à diversidade na aplicação (pp. 204-212). Santo André: Esetec.

Morais, M. L. S., O tta, E., \& Scalla, C. T. (2001). Status sociométrico e avaliação de características comportamentais: um estudo de competência social em pré-escolares. Psicologia: Reflexão e Crítica, 14(1), 119-131.

Pettit, G. S., Bates, J. E., \& Dodge, K. (1997). A Supportive parenting ecological context and children's adjustment: a seven year longitudinal study. Child Development, 67(5), 908-923.

Roberts, R. N., Wasik, B. H., Cast, G., \& Ramey, C. T. (1991). Family support in the home, programs, policy and social. American Psychologist, 46(2), 131-137.

Royer, E. (1999). Understanding emotional and bahavioural difficulties: a canadian perspective, Emotional and behavioural difficulties: a peer. Review Journal, 4(1), 28-34.
Silvares, E. F. M. (2000). Terapia comporta-mental com famílias de crianças agressivas: Por que, como e quando. (pp. 25-32). Paidéia. Ribeirão Preto: FFCLRP - USP.

Weber, L. N. D., Viezzer, A. P., \& Brandenburg, O. J. (2003). Estilos parentais e desenvolvimento da criança e do adolescente. Palmadas e surras: ontem, hoje e amanhã. In M. Z. S. et al. (O rg.). Sobre comportamento e cognição: A história e os avanços, a seleção por conseqüências em ação. (pp. 512526). Santo André: Esetec.

Zamberlan, M. A. T. (2003). Psicologia e prevenção: Modelos de intervenção na infância e na adolescência. Londrina: EDUEL.

Recebido: 11/ 12/ 2007

Received: 12/ 11/ 2007

Aprovado: 06/ 06/ 2008 A pproved: 06/ 06/ 2008 